Original Contribution

\title{
SEROPREVALENCE OF SOME VECTOR-BORNE DISEASES IN DOGS FROM PLOVDIV, BULGARIA
}

\author{
A. Arnaudov $1,2^{*}$ \\ ${ }^{1}$ Department Public Health and Health Cares, University 'Professor Dr. Asen Zlatarov', Burgas, \\ Bulgaria \\ ${ }^{2}$ Faculty of Biology, Plovdiv University 'Paisii Hilendarski', Plovdiv, Bulgaria
}

\begin{abstract}
The aim of the present study was to determine the seroprevalence and the occurrence of important some canine vector-borne diseases in the city of Plovdiv, Bulgaria. A total of 84 blood samples ( 46 from stray dogs and 38 from pets) were tested. The CANIV-4 diagnostic kit (BIONOTE) was used to detect infections with Dirofilaria immitis, Anaplasma phagocytophilum/Anaplasma platys, Borrelia burgdorferi and Ehrlihia canis. A cytological examination of blood smears was performed in order to establish causative agents. Thirty samples (65.2\%) were found positive for one or more of these causative agents. Ehrlihia canis infection was detected in 14 samples, Anaplasma phagocytophilum /Anaplasma platys in 12 samples, and an invasion with Dirofilaria immitis in 11 samples. No Borrelia burgdorferi infection was established. Co-infection was found in 7 samples. Antibodies against Ehrlihia spp. and Anaplasma spp. were detected in 5 samples and a co-infection of Anaplasma spp. with Dirofilaria immitis was observed in 2 samples. Microfilariae were observed in all blood smears from positive samples, while the Ehrlihia morulas were found only in one sample from a dog with splenomegaly and moderate cachexia.
\end{abstract}

Key words: Anaplasma phagocytophilum/Anaplasma platys, Borrelia burgdorferi, Dirofilaria immitis, Ehrlihia canis

\section{INTRODUCTION}

Canine vector-borne diseases (CVBDs) include a wide variety of diseases of infectious and parasitic aetiology, whose agents are transmitted by ectoparasites (ticks, mosquitoes, etc.). (1). They are widespread in many countries around the world and have important epidemic significance, which has increased in recent decades (2-8). CVBDs occur with high morbidity and mortality in dogs (8), some of them being zoonotic and may therefore pose a risk to the public health (9). In Europe, these diseases are most prevalent in the Mediterranean countries (10). Recently, however, there has been a tendency to expand their prevalence due to climate change leading to the expansion of the areals of their vectors (4, 11, 12). According to Genchi et al. (11)

\footnotetext{
Correspondence to: A. Arnaudov, University “Prof. Dr. As. Zlatarov"-Burgas, Dep. Public Health and Health Cares, Phone+359-889206757, arny87@abv.bg
}

these diseases are also expected to occur in European countries where they have not been present previously. Thus, in recent years, there has been an expansion of dirofilariasis in dogs to countries in Central and Northern Europe (10).

In Bulgaria, CVBDs have been found relatively recently, with the first studies being conducted in the 1990s and at the beginning of this century.

Tsachev (13) and Tsachev et al. $(14,15)$ for the first time carried out seroepidemiologic studies of the prevalence of Ehrlihia canis (E. canis) initially in the Plovdiv region, and later in other regions of Southern and Northern Bulgaria. A high percentage of dogs, seropositive for this pathogen was found, resp. $37.5 \%$ in the northern part of the country and $30 \%$ in the southern, with the highest percentage in the Plovdiv region $(75 \%$ in the first and $50 \%$ in the next study, respectively). 
Infection with Anaplasma phagocytophilum (A. phagocytophilum) in Bulgaria was first found and studied by Tsachev et al. (16) in an 8-yearold dog in Stara Zagora. Subsequent studies have shown the spread of the disease only in the southern regions $(3.5 \%$ in Plovdiv and $17.4 \%$ in Stara Zagora), but not in Northern Bulgaria (17).

The first cases of dirofilariasis in dogs in Bulgaria were identified by Georgieva et al. 2001 in 1997 - 1999 among pets and stray dogs, where the percentage of seroprevalence was 1.4 and 12.5, respectively (17). Later Kirkova et al. (18) found that dirofilariasis in Southern Bulgaria is mainly caused by Dirofilaria immitis (D. immitis) $(9.2 \%)$ and to a lesser extent by Dirofilaria repens (1.4\%). The presence of $D$. immitis has been described and studied in some regions of the country (according to Pantchev et al., 9), including in the capital Sofia (19), where the percentage of seroreagents was the highest $(31.25 \%$ among stray dogs). In Plovdiv and the adjacent settlements for 5 years (2001-2006), 87 cases of the disease were identified, and the number of newly diagnosed animals increased every year (20).

The first test for infection with Borrelia burgdorferi (B. burgdorferi) in dogs in Bulgaria was performed by Anguelov et al. (21), who reported a seroprevalence of $74.5 \%$ in enzootic regions (not specified). Later studies by Zarkov and Marinov (22), Martinov et al. (23) and Tsachev and Petrov (24) demonstrate a low prevalence of the infection.

The prevalence of other CVBDs such as canine visceral leishmaniosis, as well as diseases caused by Babesia canis and Hepatozoon canis (9) have also been studied.

Studies on the prevalence of CVBDs have been conducted in Bulgaria's neighbouring and nearby countries $(10,25-28)$.

The review of the publications shows that CVBDs are prevalent in Bulgaria, incl. the region of Plovdiv. The last presented results for Plovdiv, however, are from more than ten years ago. Data on the presentation of these diseases are insufficient. Therefore, the goal of the present study was to determine the seroprevalence and the occurrence of important CVBDs in dogs from the city of Plovdiv with a focus on diseases caused by $D$. immitis, $A$.
ARNAUDOV A.

phagocytophilum /A. platys, B. burgdorferi and E. canis.

\section{MATERIAL AND METHODS}

\section{Study area}

Plovdiv $\left(42^{\circ} 14^{\prime} \mathrm{N}\right.$ and $24^{\circ} 74^{\prime \prime} \mathrm{E}$, altitude - 160 $\mathrm{m})$ is the second-largest city of Bulgaria (approx. 350000 population). It is situated in south-central Bulgaria on the two banks of the Maritsa River (Figure 1,

https://www.stepmap.com/map/plovdiv-

hl3b63ZzyZ-i). The Plovdiv area has a humid climate that is mild, with no dry season (yearround rainfall). Seasonality is moderate (Köppen-Geiger classification - Cfa). According to the Holdridge life zones system of bioclimatic classification Plovdiv is situated in or near the cool temperate steppe biome (www.plovdiv.climatemps.com). The town is an important industrial and transport center. Agriculture and livestock are highly developed in the area around it.

According to the Municipality of Plovdiv, the number of stray dogs in the city in 2019 was 515. From 17.12.2017 to date, 9219 pet dogs have been officially registered in the Municipality of Plovdiv (https://www.plovdiv.bg/item/ecology).

\section{Animals and sample collection}

During the period April 2018 - October 2019, a total of 84 blood samples from dogs (45 males and 37 females) were tested, of which 46 blood samples from stray dogs residing on the territory of municipal enterprise "Zoo veterinary Complex" - Plovdiv (24 males and 22 females) and 38 from pets, randomly selected patients of the Veterinary Clinic "St. George" - Plovdiv (21 males and 15 females). The tested samples were from dogs caught (respectively living) in the six neighbourhood of Plovdiv.

All stray dogs studied were mixed breed, while domestic dogs were various pure breeds.

A $5 \mathrm{ml}$ blood sample was obtained from v. saphena of each dog using tubes with anticoagulant (EDTA) in compliance with all rules for biosecurity and animal welfare.

\section{Serologic assay}

The obtained samples were tested with CANIV4 diagnostic kits (BIONOTE), for detection of $D$. immitis antigen and antibody against $A$. phagocytophilum/A. platys, B. burgdorferi and 
E. canis. Whole blood was used for this purpose according to the manufacturer's instructions.

\section{Additional tests}

All studied animals were observed for the clinical presentation of the disease - general condition, nutrition, eye condition, and vision (only in the ones seropositive for $A$. phagocytophilum/A. platys and E. canis), pathological leaks from natural orifices. During the operation, if possible, the spleen was palpated to detect possible splenomegaly.

Blood smears were also prepared from the positive samples for microscopic examination.
ARNAUDOVA.

The smears were stained with a kit for instant colouring DKK Color-200 (VIVA-MT, Bulgaria) and were observed with an Olympus CX22LED light microscope for the presence of intracytoplasmic inclusions and morulae or the body of the parasites.

\section{Statistical analysis}

Seropositivity rates were compared according to lifestyle (stray and pets) and sex (male or female). Associations between seropositivity and the remaining variables were assessed using the chi-squared test and Student-t test. Significance was set at $\mathrm{p} \leq 0.05$.

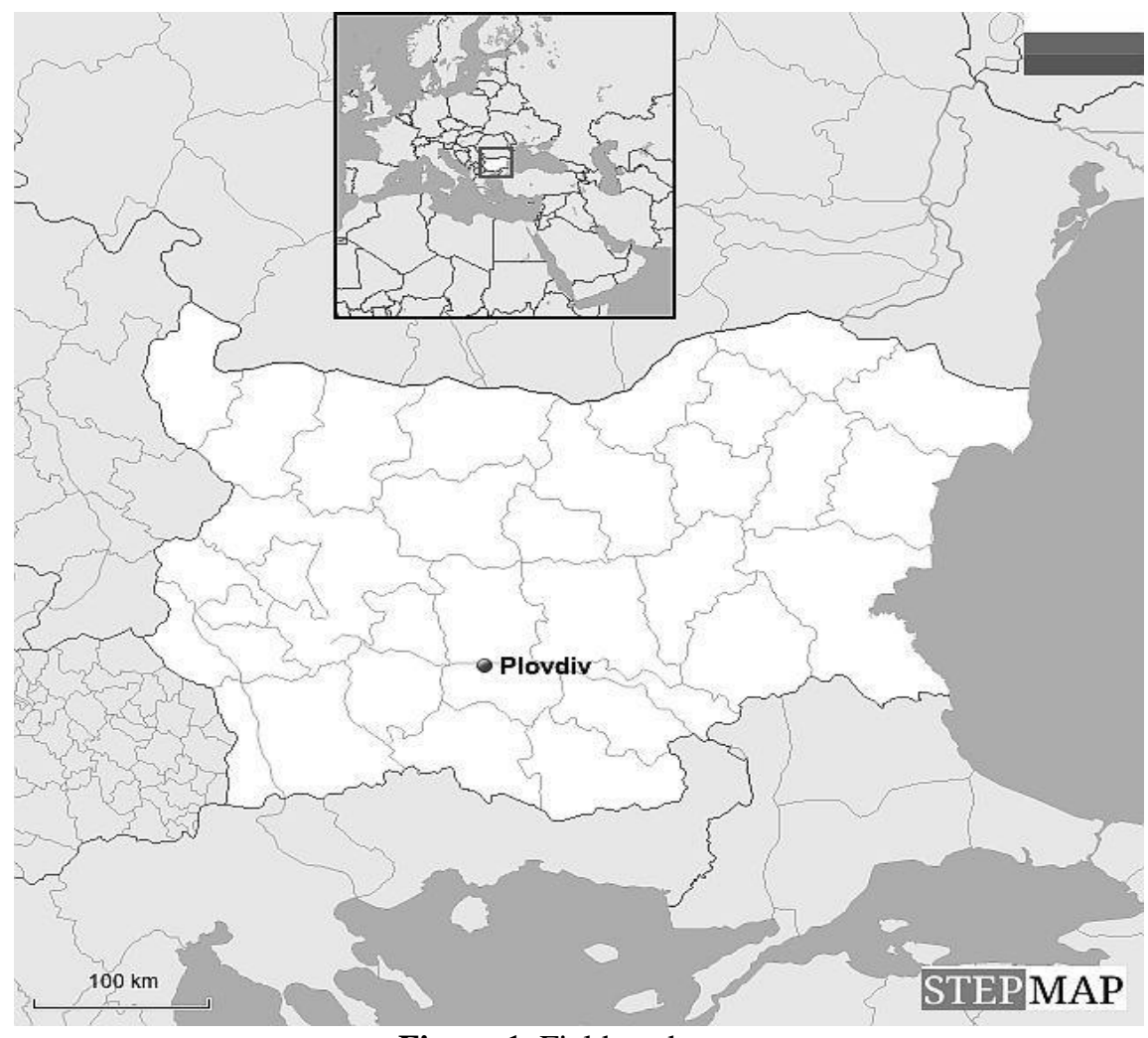

Figure 1. Field study area

\section{RESULTS AND DISCUSSION}

The data on the identified seroreagents, broken down by lifestyle and sex are presented in Table $\mathbf{1}$.

Table 1. The frequency (number) and prevalence (in \%) of vector-borne pathogens dogs from Plovdiv, Bulgaria broken down by lifestyle and sex

\begin{tabular}{|c|c|c|c|c|c|c|c|c|c|c|c|}
\hline \multirow[t]{2}{*}{$\begin{array}{c}\text { Category } \\
\text { dogs }\end{array}$} & \multirow[t]{2}{*}{$\begin{array}{c}\text { Dogs } \\
\text { examined }\end{array}$} & \multirow{2}{*}{$\begin{array}{c}\text { Total } \\
\text { number } \\
\text { and \% of } \\
\text { seroreagents }\end{array}$} & \multirow[t]{2}{*}{$\mathbf{D i}^{\mathbf{a}}$} & \multirow[t]{2}{*}{$\mathbf{E c}^{\mathbf{b}}$} & \multirow[t]{2}{*}{$A p^{c}$} & \multirow[t]{2}{*}{$\mathbf{B b}^{\mathbf{d}}$} & \multirow[t]{2}{*}{$\mathbf{E c}+\mathrm{Ap}^{\mathrm{e}}$} & \multirow[t]{2}{*}{$A p+D i^{f}$} & \multicolumn{3}{|c|}{$\begin{array}{c}\text { Total number and \% of } \\
\text { seroreagents } \\
\text { (both infection an co-infection): }\end{array}$} \\
\hline & & & & & & & & & $\mathbf{D i}^{\mathbf{a}}$ & $\mathbf{E c}^{\mathbf{b}}$ & $\mathbf{A p ^ { c }}$ \\
\hline $\begin{array}{l}\text { I. life style } \\
\text { 1. Outdoor } \\
\text { 2. Indoor }\end{array}$ & $\begin{array}{l}46 \\
38 \\
\end{array}$ & $\begin{array}{c}30 / 65.2 \\
4 / 10.5\end{array}$ & $\begin{array}{c}9 / 19.5 * * \\
4 / 10.5\end{array}$ & $\begin{array}{c}9 / 30.4^{*} \\
0 / 0\end{array}$ & $\begin{array}{c}5 / 10.9^{*} \\
0 / 0\end{array}$ & $\begin{array}{l}0 / 0 \\
0 / 0\end{array}$ & $\begin{array}{c}5 / 10.9^{*} \\
0 / 0\end{array}$ & $\begin{array}{c}2 / 4.3^{*} \\
0 / 0 \\
\end{array}$ & $\begin{array}{c}11 / 23.9 * * \\
4 / 10.5\end{array}$ & $\begin{array}{c}14 / 30.4^{*} \\
0 / 0\end{array}$ & $\begin{array}{c}12 / 26.1^{*} \\
0 / 0\end{array}$ \\
\hline $\begin{array}{ll}\text { II. Gender } \\
\text { 1. } \quad \text { Male } \\
\text { 2. } \quad \text { Female }\end{array}$ & $\begin{array}{l}45 \\
37 \\
\end{array}$ & $\begin{array}{c}21 / 46.6 * * \\
13 / 35.1\end{array}$ & $\begin{array}{c}8 / 17.8^{* * *} \\
5 / 13.5 \\
\end{array}$ & $\begin{array}{c}5 / 11.1^{* *} * \\
4 / 10.8 \\
\end{array}$ & $\begin{array}{c}3 / 6.7 * * \\
2 / 5.4\end{array}$ & $\begin{array}{l}0 / 0 \\
0 / 0\end{array}$ & $\begin{array}{c}4 / 8.8^{* * *} \\
1 / 2.7 \\
\end{array}$ & $\begin{array}{c}1 / 2.2 * * \\
1 / 2.7 \\
\end{array}$ & $\begin{array}{c}9 / 19.5^{* *} \\
6 / 16.2 \\
\end{array}$ & $\begin{array}{l}9 / 19.5 \\
5 / 13.5\end{array}$ & $\begin{array}{l}7 / 15.55 \\
5 / 13.51 \\
\end{array}$ \\
\hline
\end{tabular}

${ }^{a}$ D. immitis, ${ }^{\mathrm{b}}$ E. canis, ${ }^{\mathrm{c}}$ A.phagocyticum/platis, ${ }^{d}$ B. burgdorferi, ${ }^{\mathrm{e}}$ E. canis + A.phagocyticum/platis co-infection, ${ }^{\mathrm{f}}$

D. immitis + A.phagocyticum/platis co-infection, ${ }^{*} \mathrm{p}<0.01, * * \mathrm{p}>0.05$ 
From the total of 46 studied blood samples from stray dogs, only 16 of them $(34.8 \%)$ showed a negative result, and in the remaining 30 samples $(65.2 \%)$ a positive result was found as follows: 14 samples $(30.4 \%)$ for E. canis, 12 samples (26.1\%) for A. phagocytophilum/A. platys, and 11 samples (23.9\%) for D. immitis. Antibody agains $B$. burgdorferi was no found. This negative finding correlates with the data of researchers from both Bulgaria and other countries, according to which the percentage of dogs seropositive for $B$. burgdorferi is very low $(8,9,22-25,28)$.

The percentage of seropositive dogs for one or more pathogens we found is remarkably close to the data of Panchev et al. (9) for the region of St. Zagora $(64.7 \%)$. From this it can be concluded that in the studied regions of Bulgaria the prevalence of these diseases is wider than in neighbouring and nearby countries - Greece $-21.8 \%$ (25), Hungary $13 \%$ (28) and Romania $11.3 \%$ (8).

In 7 samples coinfection was found - for 5 samples coinfection of A. phagocytophilum / A. platys and E. canis and for 2 samples coinfection of A. phagocytophilum / A. platys and $D$. immitis. Therefore, the total percentage of seroreagents (80.4) is higher than the actual one $(65.2 \%)$.
Of the studied 38 samples from dogs kept indoors only 4 of them showed a positive result $(10.5 \%)$. All seroreagents were infested with only $D$. immitis. The total number of seropositive dogs kept indoors is significantly lower than the number of seropositive stray dogs $(\mathrm{p}<0.01)$.

\section{Dirofilaria immitis}

No significant differences were found between the number of seropositive stray and pet dogs for D. immitis, as well as between male and female animals $(p>0.05)$. In this respect, our results coincide with those of Yildirma et al. (29) who did not find a significant difference between the percentage of seropositive pet and stray dogs in the Kaysery area, Turkey.

No changes in the general condition of the studied animals were observed.

Mature forms D. immitis were found in blood smears from the seroreagents (Figure 2).

The study confirms the conclusion of Stoyanova et al (19) that the spread of the disease in Bulgaria and in Europe in recent years is increasing. It can also be concluded that dirofilariasis is more common in the studied regions of Bulgaria (Sofia, Plovdiv and Stara Zagora) compared to neighbouring and nearby countries $(8,25,26,28)$, where the percentage of seropositive dogs is between 2.4 to 9.6.

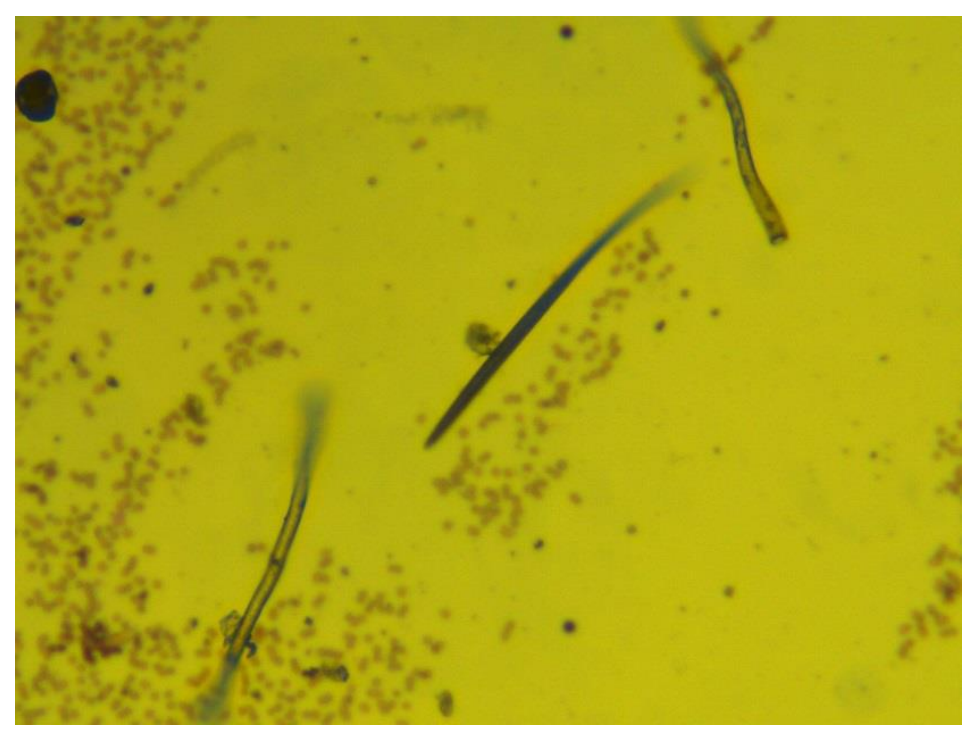

Figure 2. D. immitis in blood stream.HEx200

\section{Ehrlihia canis}

This infection was found only in stray dogs. Although the number and percentage of seropositive dogs were higher in males, no significant difference was found in the infection rates of the two sexes with E. canis (p>0.05).
This is similar to the conclusion of Tsachev et Kontos that the spread of the disease does not depend on the sex and age of the dogs (14).

Our results for the spread of ehrlichiosis in dogs are remarkably close to the results obtained by Tsachev for Southern Bulgaria and 
the more recent data of Panchev et al. (9) for Stara Zagora (21\%), as well as with the data of Pavlovic et al. (27) for Belgrade area $(28.35 \%$ seropositive dogs kept in a shelter) and the data of Cetinkaya et al. (26) for cities in Eastern Thrace (Turkey) - 27.25\%. Similar to the data of Angelou et al. (25) for the spread of ehrlichiosis in Greece, our results showed that this disease is the most widespread of the CVBDs in the Plovdiv region. This can be explained by the widespread prevalence of the disease vector-Rhipicephalus sanguineus (13).
ARNAUDOV A.

This tick is a common vector of $E$. canis and $A$. platys, which may explain the fact that the most common coinfection with CVBDs in Bulgaria is ehrlichiosis and anaplasmosis (9).

Moderate cachexia was found in 4 dogs and splenomegaly in one dog.

In the cytological examination of blood smears, morulae of $E$. canis were observed in only one sample, in a monocyte of dog with splenomegaly and moderate cachexia (Figure 3).

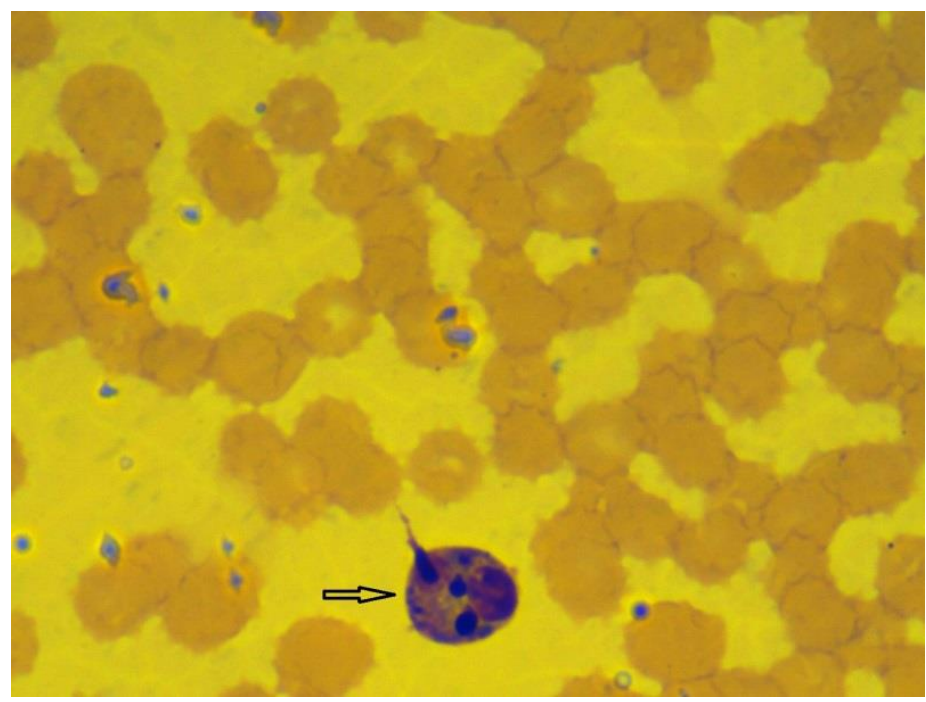

Figure 3. Morulae of E. canis in monocyte (arrow).HEx600

\section{Anaplasma phagocytophilum/Anaplasma platys}

The results obtained for this infection were similar to those for the infection with E. canis. The disease was found only in stray dogs, with no significant difference between the number of infected males and females ( $p>0.05)$. No morulae of anaplasmas were observed during the cytological examination. No changes in the general condition of the infected animals were found. As in ehrlichiosis, in anaplasmosis morulae are found only in the acute form of the disease (30).

The results obtained for the spread of anaplasmosis among dogs in Plovdiv are closest to the data of Pavlovic et al. (28) for Belgrade, where the percentage of seropositive dogs kept in a shelter is 19.40. Our data is significantly higher than that of Tsachev (according to 9) for Plovdiv since 2009 (3.5\% seropositive), which shows that in one decade the spread of the disease in the city has increased more than seven times. This suggests paying serious attention to the disease, given that dogs (mainly stray dogs) have important epidemiological significance as an important reservoir of infection (16). The control of the disease is further complicated, as it is mainly asymptomatic and cytological examinations often give a false negative result. This requires periodic screening with serological and PCR tests to obtain real information about the scope and prevalence of anaplasmosis in canine populations.

\section{CONCLUSIONS}

Widespread ehrlichiosis, dirofilariasis and anaplasmosis have been found among dogs in the city of Plovdiv. The diseases were found mainly among stray dogs, and the only dirofilariasis was found among pets. The diseases are mainly asymptomatic.

\section{ACKNOWLEDGMENT}

I would to thank the management and the team of veterinary specialists of ME "Zoo veterinary Complex"-Plovdiv, as well as the Manager of the Veterinary Clinic "St. George" -Plovdiv, Dr. Georgi Syarov, and Dr. Marina Syarova for their help during the collection of blood samples from the dogs. 
CONFLICT OF INTEREST STATEMENT

The author has no conflicts of interest to declare.

\section{REFERENCES}

1. Otranto, D., Dantas-Torres, F., Breitschwerdt, E. B. Managing canine vector-borne diseases of zoonotic concern: part two. Trends Parasitol, 25, 5: 228-235, 2009.

2. Procajlo, A., Mikulska-Skupien, E., Bladowski, M., Lew, S. Monocytic ehrlichiosis in dogs. Pol J Vet Sci, 14, 3 :515520, 2011.

3. Rizzoli, A., Hauffe, H., Carpi, G., Vourc'h, G., Neteler, M., Rosa, R., Lyme borreliosis in Europe. Eurosurveillance, 16, 27: 1-8, 2011.

4. Morchón, R., Carretón, E., González Miguel, J. and Mellado Hernández, I., Heartworm disease (Dirofilaria immitis) and their vectors in Europe-new distribution trends. Front physiol, 3, 196: 1-11, 2012.

5. Cohn, L., Ehrlichiosis and related infections. Vet Clin North Am: Small Anim Prac, 33, 4:863-884, 2003.

6. Miró, G., Montoya, A., Roura, X., Gálvez, R. and Sainz, A., Seropositivity rates for agents of canine vector-borne diseases in Spain: a multicentre study. Parasites Vectors, 6,1:1-9, 2013.

7. Shaw, S. E., Day, M. J., Birtles, R. J., Breitschwerdt, E. B. Tick-borne infectious diseases of dogs. Trends Parasitol, 17, 2:7480, 2001.

8. Sarma, K., Mondal, D., Saravanan, M. and Mahendran, K., Evaluation of haematobiochemical and oxidative indices in naturally infected concomitant tick borne intracellular diseases in dogs. Asian Pac J Trop Dis, 5, 1:60-66, 2015.

9. Pantchev, N., Schnyder, M., Vrhovec, M. G., Schaper, R., Tsachev, I. Current surveys of the seroprevalence of Borrelia burgdorferi, Ehrlichia canis, Anaplasma phagocytophilum, Leishmania infantum, Babesia canis, Angiostrongylus vasorum and Dirofilaria immitis in dogs in Bulgaria. Parasitol Res, 114, 1:117-130, 2015.

10.Mircean, V., Dumitrache, M.O., Györke, A., Pantchev, N., Jodies, R., Mihalca, A.D. and Cozma, V., Seroprevalence and geographic distribution of Dirofilaria immitis and tickborne infections (Anaplasma phagocytophilum, Borrelia burgdorferi sensu lato, and Ehrlichia canis) in dogs from
ARNAUDOV A.

and Zoonotic

Romania. Vector-borne

11.Genchi, C., Rinaldi, L., Cascone, C., Mortarino, M., and Cringoli G., Is heartworm disease really spreading in Europe?. Vet Parasitol, 133, 2-3: 137-148, 2005.

12.Gray, J.S., Dautel, H., Estrada-Peña, A., Kahl, O. and Lindgren, E., Effects of climate change on ticks and tick-borne diseases in Europe. Interdiscip Perspect Infect Dis, 2009:593232, 2009.

13.Tsachev, I., Detection of Antibodies Reactive with Ehrlichia canis in a Kennel in Bulgaria. Turk J Vet Anim Sci, 30, 4:425426, 2006.

14.Tsachev, I., Kontos, V., Zarkov, I., Krastev S., Survey of antibodies reactive with Ehrlichia canis among dogs in South Bulgaria. Revue Méd Vét, 157, 10: 481-485, 2006.

15.Tsachev, I., Papadogiannakis, E.I., Kontos, V., Zarkov, I., Petrov, V., Pelagic, V., Seroprevalence of Ehrlichia canis infection among privately-owned dogs in northern Bulgaria. J Hell Vet Med Soc, 57, 3: 212216, 2006.

16.Tsachev, I., Petrov, V., Flaming, K. and Brown, C., First detected case of Anaplasma phagocytophilum in a dog in Bulgaria. Revue Méd. Vét, 159,11:562-564. 2008.

17. Georgieva, D., Kirkova, Z. and Ivanov, A., A study on the incidence and diagnostics of dirofilariosis (Heathworm disease) in carnivores. Bulg J Vet Med, 4, 4:231-236, 2001.

18.Kirkova, Z., Ivanov, A., Georgieva, D., Prelesov, P., An update on dirofilariosis in dogs and wild canines in Bulgaria. Sbornik dokladi ot nauchnata konferentsiya: Traditsii i s'vremenhost v'v veterinarnata meditsina, 247-252.2008 (in Bulgarian).

19.Stoyanova, H., Carretón, E., MontoyaAlonso, J. A. Stray dogs of Sofia (Bulgaria) could be an important reservoir of heartworm (Dirofilaria immitis). Helminthologia, 56, 4:329-333, 2019.

20.Kostadinov, M., Dirofilariosis among dogs in a small animal practice in the Plovdiv region, Bulgaria. Dirofilaria immitis and $D$. repens in dog and cat and human infections. Naples, Italy: Rolando Editore, 205. 2007.

21.Angelov, L., Arnaudov, D., Rakajieva, T., Kostova, E., Studies of epizootiological process with Lyme borreliosis in Bulgaria. Infectology, 5: 12-14. 1993 
22.Zarkov, I., and Marinov, M., The lyme disease: results of a serological study in sheep, cows and dogs in Bulgaria. Revue Méd Vét , 154, 5: 363-366. 2003.

23.Martinov S., Halacheva, M. N.Nedelchev, E.Aleksandrov. Contemporary state of the tick-borne transmissible infections in domestic animals in Bulgaria. Vet Med (Bulgaria), 10, 3-4: 7-18, 2006.

24.Tsachev, I., Zarkov, I., Kairakova, B., Papadogiannakis, E., Lyme borreliosis in dogs: Disyribution and epidemiology. Trakia J Sci, 6, 1: 116-122. 2008.

25.Angelou, A., Gelasakis, A. I., Verde, N., Pantchev, N., Schaper, R., Chandrashekar, R., Papadopoulos, E., Prevalence and risk factors for selected canine vector-borne diseases in Greece. Parasit Vectors, 12, 1: 111. 2019.

26.Cetinkaya, H., Matur, E., Akyazi, I., Ekiz, E. E., Aydin, L., Toparlak, M., Serological and molecular investigation of Ehrlichia spp. and Anaplasma spp. in ticks and blood of dogs,
ARNAUDOV A. in the Thrace Region of Turkey. Ticks TickBorne Dis, 7, 5: 706-714. 2016.

27.Pavlović, I. N., Kovačević, I. N., Doder, R. B., Rangelov, B. R., Nikić, I. B., Tambur. Blood parasites in dogs from the Belgrade area in the period 2014-2015. Zbornik Matice srpske za prirodne nauke, 132: 6978. 2017.

28.Farkas, R., Gyurkovszky, M., Lukács, Z., Aladics, B. and Solymosi, N., Seroprevalence of some vector-borne infections of dogs in Hungary. Vector Borne Zoonotic Dis, 14, 4 :256-260, 2014.

29. Yildirim, A.,, Ica, A., Atalay, O., Duzlu, O., Inci. A., Prevalence and epidemiological aspects of Dirofilaria immitis in dogs from Kayseri Province, Turkey. Res Vet Sci, 82, 3 : 358-363. 2007.

30.Bowman, D. D. and Atkins, C. E., Heartworm biology, treatment, and and control. Vet Clin North Am Small Anim Pract, 39, 6: 1127-1158, 2009. 